\title{
AGGREGATE EXPANSIVITY DUE TO SULFIDE OXIDATION - I. REACTION SYSTEM AND RATE MODEL
}

\author{
I. Casanova, L. Agulló and A. Aguado \\ Departament d'Enginyeria de la Construcció, Edifici C1, Universitat Politècnica de Catalunya, \\ E-08034 Barcelona, Spain.
}

\begin{abstract}
Oxidation and hydration of sulfides in aggregate materials can yield to expansive reactions that affect the durability of concrete. This process is, in principle, independent from the potential alkali-aggregate reactivity, and the oxidation of the sulfide is the rate-limiting reaction. A model is presented to evaluate the kinetic evolution of expansion due to sulfide oxidation, and subsequent sulfate attack on the paste.
\end{abstract}

\section{Introduction}

Aggregates with sulfur-bearing compounds can become a source of deleterious sulfate attack and, consequently, their utilization is restricted by most international norms. On the other hand, sulfides are ordinary minor components of a wide variety of rocks, and constitute perhaps the most abundant type of mineral ore. It is therefore difficult to avoid sulfide-bearing materials in concrete manufacture, and this problem may be aggravated in remote areas where sulfidebearing rocks may be the only kind of aggregate available (e.g. construction of dams).

Due to the limited use of aggregates with sulfur-bearing compounds, the effects of sulfide oxidation on concrete are poorly known, and only some qualitative recommendations can be found in international norms regarding this problem. Chinchón et al. (1) summarize the main types of reactions and products of iron sulfide weathering in a quarry environment, and justify the inadequacy of such materials for their use as aggregates. Many of the minerals identified as final products of this weathering process have relatively large molar volumes (or, at least, larger than their precursors) and, consequently, their formation is a source for expansive phenomena. But sulfide oxidation is very slow compared to other common expansive reactions in concrete (e.g. sulfate attack), and its experimental study is not straightforward. In this work, we propose a suitable model for the evaluation of the maximum expected magnitude of expansive phenomena due to these processes, and their evolution in time. 


\section{$\underline{\text { Reaction system and rate law }}$}

Pyrite $\left(\mathrm{FeS}_{2}\right)$ and pyrrhotite $\left(\mathrm{Fe}_{1-\mathrm{x}} \mathrm{S}\right)$ are the most abundant iron sulfides in natural rocks and, therefore, the study of their oxidation is of special interest for the evaluation of expansive reactions in sulfide-bearing aggregates (Table 1 ).

\section{TABLE 1}

Predominant oxidation reactions of pyrite and pyrrhotite in aqueous systems, and their associated volume changes. Pyrrhotite reactions balanced for $x=0.125$. Volume data from (2).

\begin{tabular}{|l|c|c|}
\hline & Reaction & $\begin{array}{c}\Delta \mathbf{V}_{\text {solids }} \\
\mathbf{3} \text { per mole of sulfide })\end{array}$ \\
\hline $\mathbf{1 a}$ & $\mathrm{FeS}_{2}+\frac{9}{2} \mathrm{O}_{2}+2 \mathrm{H}_{2} \mathrm{O} \rightarrow \mathrm{FeSO}_{4} \cdot \mathrm{H}_{2} \mathrm{O}+\mathrm{SO}_{4}^{2-}+2 \mathrm{H}^{+}$ & 209.96 \\
$\mathbf{1 b}$ & $8 \mathrm{Fe}_{1-\chi} \mathrm{S}+\frac{31}{2} \mathrm{O}_{2}+8 \mathrm{H}_{2} \mathrm{O} \rightarrow 7\left(\mathrm{FeSO}_{4} \cdot \mathrm{H}_{2} \mathrm{O}\right)+\mathrm{SO}_{4}^{2-}+2 \mathrm{H}^{+}$ & 187.08 \\
2a & $\mathrm{FeS}_{2}+\frac{9}{2} \mathrm{O}_{2}+\mathrm{H}_{2} \mathrm{O} \rightarrow \mathrm{FeOOH}+2 \mathrm{SO}_{4}^{2-}+H^{+}$ & -3.12 \\
2b & $8 \mathrm{Fe}_{1-\chi} \mathrm{S}+\frac{67}{4} \mathrm{O}_{2}+\frac{25}{2} \mathrm{H}_{2} \mathrm{O} \rightarrow 7 \mathrm{FeOOH}+8 \mathrm{SO}_{4}^{2-}+16 H^{+}$ & 0.64 \\
3a & $\mathrm{FeS}_{2}+\frac{17}{4} \mathrm{O}_{2}+\mathrm{H}_{2} \mathrm{O} \rightarrow \frac{1}{2} \mathrm{Fe}_{2} \mathrm{O}_{3}+2 \mathrm{SO}_{4}^{2-}+2 \mathrm{H}^{+}$ & -8.81 \\
4a & $8 \mathrm{Fe}_{1-\chi} \mathrm{S}+\frac{69}{4} \mathrm{O}_{2}+8 \mathrm{H}_{2} \mathrm{O} \rightarrow \frac{7}{2} \mathrm{Fe}_{2} \mathrm{O}_{3}+8 \mathrm{SO}_{4}^{2-}+16 \mathrm{H}^{+}$ & -4.34 \\
4b & $\mathrm{FeS}_{2}+\frac{18}{4} \mathrm{O}_{2}+2 \mathrm{H}_{2} \mathrm{O} \rightarrow \mathrm{Fe}(\mathrm{OH})_{3}+2 \mathrm{SO}_{4}^{2-}+\mathrm{H}^{+}$ & 3.05 \\
\hline
\end{tabular}

Volume changes listed in Table 1 represent maximum expansion at reaction completion, and therefore overestimate the potential expansivity of the aggregate. Computation of the expansion of the bulk solid requires consideration of the overall elastic properties of the body, but such analysis is beyond the scope of this paper and will be treated elsewhere. The aim of this work is to investigate the evolution of expansive phenomena through time, applying an adequate chemical kinetic model to evaluate the extent of sulfide oxidation and its effects on the aggregate and paste components.

Much of the work on sulfide oxidation kinetics has focused on the study of mine waste environments (3), where strongly acidic conditions ( $\mathrm{pH}$ typically lower than 4) exist. Early experimental studies (4) showed that the rate of sulfide oxidation is $\mathrm{pH}$-dependent at values between 4.5 and 6.0, and independent of the acidity of the system at pH below 3.5. Nicholson et al. (5) suggest that the sulfide oxidation rate is independent of $\mathrm{pH}$, for conditions maintained at $\mathrm{pH}$ values between 7.5 and 8.5. According to their work, sulfide oxidation in such systems is only a function of surface area and the equilibrium between the decomposition of the oxidation products and the adsorption of $\mathrm{O}_{2}$ on the sulfide surface. Despite the $\mathrm{pH}$ conditions in concrete are clearly alkaline, the immediate environment surrounding the reaction front is likely to be substantially more acidic due to the release of hydrogen ions during oxidation.

In view of this, we have adopted a model for sulfide weathering where the rate of reaction $(d N / d t)$ can be treated like a "shrinking core" problem (6), and formulated as 


$$
-\frac{d N}{d t}=\frac{4 \rho_{m} b C R^{2}}{\frac{R(R-r)}{r D_{s}}+\frac{R^{2}}{r^{2} k_{s}}}
$$

where $\rho_{m}$ is the sulfide molar density and $C$ is the molecular oxygen concentration (both expressed in $\mathrm{mol} \cdot \mathrm{m}^{-3}$ ); $r$ is the radius of the unreacted particle core, $R$ is the initial particle radius, $D_{s}$ is the effective diffusion coefficient for oxygen through the oxide layer, and $k_{s}$ is the surface rate constant. The term $b$ is a dimensionless constant relating the stoichiometric quantities of sulfide oxidized to oxygen consumed, effectively represented by the ratio of the molar coefficient of the solid product (sulfate/oxide/hydroxide in reactions in Table 1) divided by the molar coefficient for $\mathrm{O}_{2}$. Experimental data (7) on the oxidation of pyrite yield best-fit values ( $2 \sigma$ confidence level) of $1.08 \pm 0.30 \times 10^{-12} \mathrm{~m}^{2} \cdot \mathrm{h}^{-1}$ for $D_{s}$ and $3.07 \pm 1.41 \times 10^{6} \mathrm{~m} \cdot \mathrm{h}^{-1}$ for $k_{s}$.

\section{$\underline{\text { Evaluation of primary expansion }}$}

The volume change per mole of sulfide oxidized can be calculated as

$$
\Delta \bar{V}_{\text {primary }}=\frac{\sum_{i=1}^{n} x_{i} \cdot\left[\left(\sum_{i} v_{i} \cdot V_{i}\right)_{\text {products }}-\left(\sum_{i} \omega_{i} \cdot V_{i}\right)_{\text {reactants }}\right]}{\omega_{i}}
$$

In Eq. 2, $V_{i}$ are the molar volumes of solid products or reactants; $v_{i}$ and $\omega_{i}$ are, respectively, the stoichiometric coefficients of the solid product and sulfide for each reaction; and $x_{i}$ are the mole fractions of each sulfide in the aggregate, normalized to their sum. The volume change due to sulfide oxidation (Table 1) will be referred to as primary expansion. From a thermodynamic (equilibrium) point of view, it can be established that ferrihydrite, $\mathrm{Fe}(\mathrm{OH})_{3}$, is the predominant sulfide oxidation product under alkaline conditions, like those typical of concrete (1). This mineral may in turn undergo dehydration and transform into goethite, $\mathrm{FeOOH}$, with a subsequent volume decrease $\left(\Delta V=-6.17 \mathrm{~cm}^{3} \cdot \mathrm{mol}^{-1}\right)$; however, the kinetics of such process are poorly understood and cannot be readily incorporated into the present model. On the other hand, dehydration of ferrihydrite is unlikely to occur in concrete, where relatively moist conditions are generally retained.

\section{$\underline{\text { Sulfate attack and secondary expansion }}$}

Sulfate and hydrogen ions released into the pore solution will react with the paste components (especially tricalcium aluminate and/or portlandite) to form additional expansive phases such as gypsum, monosulfoaluminate and, eventually, ettringite (Table 2). Such process will be referred to as secondary expansion throughout this paper. 
TABLE 2

Secondary expansion reactions induced by sulfate attack of cement components.

\begin{tabular}{|c|c|c|}
\hline & Reaction & $\begin{array}{c}\Delta V_{\text {solids }} \\
\left(\mathrm{cm}^{3} \text { per mole of sulfate }\right)\end{array}$ \\
\hline 7 & $\mathrm{CH}+\overline{\mathrm{S}}+2 \mathrm{H}^{+} \rightarrow \mathrm{C} \overline{\mathrm{S}} \mathrm{H}_{2}$ & 41.63 \\
\hline 8 & $C H+C_{3} A+\bar{S}+11 H \rightarrow C_{4} A \bar{S} H_{12}$ & 182.89 \\
\hline 9 & $3 C H+C_{3} A+3 \bar{S}+29 H \rightarrow C_{6} A \overline{S_{3}} H_{32}$ & 172.19 \\
\hline
\end{tabular}

The predominance of one or another reaction will be controlled by $\mathrm{pH}$ and the availability of sulfate ions from external sources or, in this case, sulfide oxidation. Formation of gypsum $\left(C \bar{S} H_{2}\right)$ is preferable at $\mathrm{pH}<10.5$, while ettringite $\left(C_{6} A \overline{S_{3}} H_{32}\right)$ will be favored at $10.5<\mathrm{pH}<11.5$, and calcium aluminate monosulfate $\left(C_{4} A \bar{S} H_{12}\right)$ at $\mathrm{pH}>11.5$. Therefore, reaction 7 may be ruled out as a principal contributor to secondary expansion due to the alkaline conditions in concrete.

The volume change associated with secondary expansion can be calculated from:

$$
\begin{gathered}
\Delta \bar{V}_{\text {secondary }}=\mathfrak{R} \times\left[V_{\text {product }}-\left(\sum_{i} \mu_{i} \cdot V_{i}\right)_{\text {reactants }}\right] \\
\text { where } \mathfrak{R}=\frac{\psi_{\bar{S}}}{\mu_{\bar{S}}}
\end{gathered}
$$

In Eq. 3, $\mu_{i}$ are the stoichiometric coefficients of the solid reactants in Table 2 (portlandite and/or tricalcium aluminate); $\psi_{\bar{S}}$ and $\mu_{\bar{S}}$ are the stoichiometric coefficients of sulfate in reactions listed in Tables 1 and 2, respectively. The $\mathfrak{R}$ factor arises from the assumption that all sulfate ions produced by sulfide oxidation are consumed in the secondary expansion reaction.

\section{$\underline{\text { Rate of expansion }}$}

When the external contribution of sulfates is negligible, the rate of secondary expansion will be controlled by the kinetics of sulfide oxidation, since reactions in Table 2 are fast compared to any of the oxidation processes described above. The effect of the oxidation of sulfides in aggregates on the evolution of expansive phenomena with time can now be evaluated with a chemical kinetic model such as that expressed in Eq. 1. It must be kept in mind that the present approach does not take into account the effect of porosity or the topology of sulfide grains in the aggregate rock (e.g. veins vs. isotropic arrangement, or grain size distribution). However, the model permits an evaluation of the maximum expansion due to sulfide oxidation, as well as the velocity at which the expansive phenomena are expected to occur. This is useful for predicting the potential deleterious effects of a given quantity of sulfides present in the aggregates.

The rate of expansion can be expressed as 


$$
\frac{d V}{d t}=\frac{d N}{d t} \cdot\left[\Delta \bar{V}\left(t_{\infty}\right)\right]
$$

where $\Delta \bar{V}\left(t_{\infty}\right)$ is the overall volume increase when all sulfide is oxidized (reaction completion), such that

$$
\Delta \bar{V}\left(t_{\infty}\right)=\Delta \bar{V}_{\text {primary }}+\Delta \bar{V}_{\text {secondary }}
$$

A graphical expression of Eq. 4 is given in Figure 1.

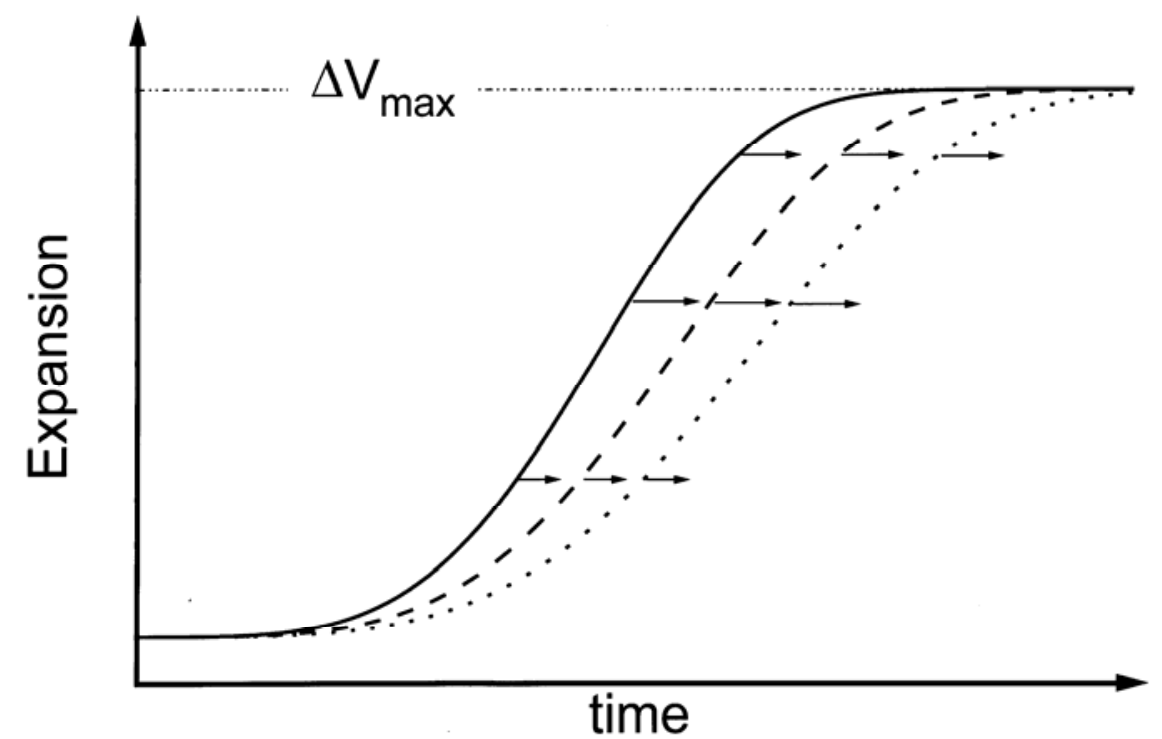

FIG. 1 Evolution of expansion phenomena. Arrows indicate trends for increasing grain size of reactants.

As mentioned above, the progress of the reaction is limited by the effective diffusion of oxygen through the oxide (hydroxide) layer that forms around the sulfide grain and the subsequent change in surface area, expressed by the rate law in Eq. 1. However, the kinetics of the process also depend on the availability of oxidizing agents. This is specific for each environmental constraint and type of concrete (e.g. subaerial or submerged, shell structures or massive concrete), and depends on a variety of parameters, including oxygen content in surrounding water and effective diffusivity of water and oxygen through concrete and aggregate materials. Research is in progress to include such considerations in the model and provide a solution that is more suitable for direct comparison with observations of expansion phenomena in sulfide-bearing aggregates and concrete structures.

\section{$\underline{\text { Summary and Conclusions }}$}

The effects of sulfide oxidation on aggregate expansion and sulfate attack of the cement are chiefly controlled by the kinetics of the weathering process, which is the rate-limiting step. The progress of the expansive reaction is governed by the change in surface area of the reactants and, therefore, depends strongly on the original grain size of the sulfides in the aggregate. Under alkaline conditions, ferrihydrite is the most stable product of sulfide oxidation; however, the 
volume increase associated with its formation is small compared to that of monosufate or ettringite production from reaction of sulfate ions with portlandite and or tricalcium aluminate.

\section{Acknowledgements}

We wish to thank E. Vàzquez and R. Gettu (UPC) for helpful comments, and C. Ayora (Institut Jaume Almera, CSIC) for orientation during the early stages of this work. This is part of a continuing investigation on the kinetics of expansive phenomena, partially supported by the UPC-FECSA Research Contract C-2218 (A. Aguado, P.I.), and the Direcció General de Recerca, Generalitat de Catalunya (Ajuts a Grups Consolidats, 1995).

\section{References}

1. CHINCHÓN, C. AYORA, A. AGUADO and F. GUIRADO, Cement and Concrete Research 25: 1264-1272 (1995)

2. ROBIE, B.S. HEMINGWAY, and J.R. FISHER, U.S. Geological Survey Bulletin No. 1452 (1978)

3. JAMBOR and D.W. BLOWES (eds.), The Environmental Geochemistry of Sulfide MineWastes, Mineralogical Association of Canada, 438 pp. (1994)

4. SINGER and W. STUMM, Science 167: 1121-1123 (1970)

5. NICHOLSON, R.W. GILLHAM and E. REARDON, Geochimica et Cosmochimica Acta 52: 1077-1085 (1988)

6. LEVENSPIEL, O. Chemical Reaction Engineering, Wiley, New York, (1972)

7. NICHOLSON, R.W. GILLHAM and E. REARDON, Geochimica et Cosmochimica Acta 54: 395-402 (1990) 